\title{
Wat draagt het doen van diensten bij aan de opleiding tot internist?
}

\author{
J.G. Zijlstra, M. Stegeman, D.Th. Sleijfer, T.S. van der Werf, R.O.B. Gans
}

\section{Samenvatting}

Inleiding: De opleiding tot internist is in een fase van vernieuwing, waarbij efficiëntie en effectiviteit grote aandacht krijgen. Het is daarom belangrijk te onderzoeken wat de bijdrage is van de verschillende onderdelen aan de opleiding en hoeveel tijd zij in beslag nemen. Hier beschrijven wij wat het doen van dienst bijdraagt aan de opleiding.

Methode: Aan de hand van de eindtermen zoals die staan beschreven in het Raamplan Interne Geneeskunde, hebben wij de pathologie die wordt aangeboden tijdens de dienst gerubriceerd. Ook is het aantal uren dat aan dienst wordt besteed onderzocht.

Resultaten: Het aanbod aan pathologie is aanzienlijk minder frequent en bovendien eenvormig. Het aantal uren dat aan het doen van dienst word besteed komt vrijwel overeen met twee volledige stage periodes. Daarmee is het doen van dienst voor de opleiding niet efficiënt. Effectiviteit wordt nauwelijks gemeten in de opleiding, maar gezien de gefragmenteerde supervisie tijdens diensten is de effectiviteit van het doen van diensten waarschijnlijk niet optimaal.

Bespreking: Voor de opleiding tot internist is het doen van dienst niet efficiënt en waarschijnlijk niet effectief. De eindtermen van het Raamplan kunnen ook op andere wijze worden behaald, bijvoorbeeld in een stage acute geneeskunde zoals die beschreven staat in de nieuwe opleidingseisen. Het doen van dienst heeft wel een belangrijk aspect van bedrijfsvoering. (Zijlstra JG, Stegeman M, Sleijfer DTh, Werf TS van der, Gans ROB. Wat draagt het doen van diensten bij aan de opleiding tot internist? Tijdschrift voor Medisch Onderwijs 2003;22(6): 258-267.)

\section{Inleiding}

Patiëntenzorg beperkt zich niet tot kantooruren, maar vindt ook daar buiten plaats. Daarom hebben dokters dienst, ook tijdens hun opleiding. Aan het doen van diensten door assistent-geneeskundigen-in-opleiding (AGIO's) zitten twee aspecten: het aspect van bedrijfsvoering en het opleidingsaspect. Terugkijkend op hun opleidingstijd, beschouwen de meeste internisten het doen van dienst als een waardevol en leerzaam onderdeel van de opleiding. Ook nu nog vinden de meeste assistent-geneeskundigen dat het doen van diensten bijdraagt aan hun opleiding. ${ }^{1}$ Er is echter een aantal ontwikkelingen die het noodzakelijk maakt deze sub- jectieve meningen tegen het licht te houden. ${ }^{2-6}$

De scholingstijd wordt effectief verkort omdat er nu, gezien de huidige arbeidsmarkt, vaak geen sprake meer is van een periode als assistent-geneeskundige-nietin-opleiding (AGNIO) voorafgaand aan de opleiding. Daarnaast worden studenten tegenwoordig geschoold in aandachtsgebieden, waar zij voorheen pas na de voltooiing van de algemene opleiding in opgeleid werden. Verder heeft de strikte naleving van de arbeidstijdbesluiten er toe geleid dat de werktijd ook nog is verkort, omdat het doen van dienst moet worden gecompenseerd in vrije tijd. 
Op grond van deze ontwikkelingen wordt het onmogelijk om alleen met de onderwijsmethode waar tot nu toe vooral mee is gewerkt, de meester-gezel situatie, het doel van 'een goed opgeleide internist' te halen. Deze methode is immers vooral gebaseerd op zo veel mogelijk patiëntencontact. Er zijn daarnaast ook andere vormen van onderwijs noodzakelijk, zoals cursorisch onderwijs en trainingen in een skillslab en een elektronische leeromgeving (ELO). Om de verkorting van de scholingstijd en de inpassing van nieuwe leermiddelen mogelijk te maken moet de efficiëntie en effectiviteit van de verschillende leermiddelen opnieuw worden beoordeeld. In dit kader hebben wij de waarde van het doen van diensten voor de opleiding van assistent-geneeskundigen in de interne geneeskunde onderzocht. Hiertoe wordt 'het doen van dienst' geëvalueerd als middel om de eindtermen uit het Raamplan Interne Geneeskunde 2002 (het Raamplan) te behalen. ${ }^{7-8}$

Het Raamplan is een document waarin de eindtermen worden beschreven die een assistent-geneeskundige moet beheersen bij het beëindigen van de opleiding. Het is als het ware de productomschrijving van een internist. Hieruit volgt automatisch dat de opleiding zodanig moet zijn ingericht dat deze eindtermen kunnen worden behaald. De eindtermen zijn verdeeld in algemene eisen en in klinische presentaties en ziektebeelden. Onder algemene eisen worden bijvoorbeeld verstaan het goed kunnen afnemen van een anamnese, het goed kunnen uitvoeren van een lichamelijk onderzoek en het vertonen van een goed probleemoplossend vermogen. In principe kunnen algemene eisen geleerd worden aan de hand van een willekeurige patiëntenpopulatie. Onder klinische presentaties worden verstaan afwijkingen waar patiënten zich mee presenteren (bijvoorbeeld koorts of slikklachten). Ziekte- beelden zijn entiteiten met een klinische presentatie, een pathofysiologisch mechanisme, een diagnostisch traject en een behandeling. Om deze eindtermen aan de hand van patiëntencontacten te leren is een bepaalde samenstelling van de patiëntenpopulatie wel noodzakelijk. Bij elk leermiddel, zoals een klinische stage er één is, zal worden getracht de algemene eisen en de kennis van klinische presentaties en ziektebeelden te integreren. Per leermiddel zullen er echter verschillende accenten zijn. Tijdens de poliklinische stage zal bijvoorbeeld sterke integratie van alle eindtermen plaatsvinden. Tijdens een vaardigheidstraining in communicatie zal uiteraard de nadruk liggen op een algemene eis.

Een tweede document dat voor de inrichting van de opleiding van belang is, de Opleidingseisen, beschrijft de eisen die worden gesteld aan de opleiding, de opleider en de opleidingsinrichting. ${ }^{9}$ Ten aanzien van de invulling van de opleiding worden ook eisen gesteld. Zo moet het eerste jaar van de opleiding bestaan uit algemene interne geneeskunde en worden stages onderscheiden in verplichte stages, voorkeurstages en facultatieve stages. Een stage 'dienst doen' is echter niet opgenomen. Wel bestaat de mogelijkheid van een facultatieve stage acute interne geneeskunde. De opleiding bestaat aldus uit een aantal verplichte onderdelen die door iedere assistent-geneeskundige moeten worden gevolgd en een aantal niet-verplichte onderdelen waaruit een keuze kan worden gemaakt. Als gegarandeerd moet worden dat iedere assistent-geneeskundige de eindtermen uit het inhoudelijke document, het Raamplan, moet kunnen behalen, dan kan dat alleen via het volgen van verplichte onderwijsvormen zoals daar zijn verplichte stages en cursussen.

Hier beschrijven wij de eindtermen van het Raamplan 2002 die tijdens het doen 
van diensten kunnen worden bereikt. Om tot een oordeel te kunnen komen over efficiëntie en effectiviteit worden deze afgezet tegen het aantal uren dat naar schatting tijdens de opleiding aan diensten wordt besteed.

\section{Methode}

\section{Tijdsbesteding}

Het aantal uren dat assistent-geneeskundigen aan diensten besteden is berekend op basis van roosters zoals die binnen de afdeling Interne Geneeskunde van het Academisch Ziekenhuis Groningen worden gehanteerd. De uren die vijf representatieve assistent-geneeskundigen gedurende een periode van acht maanden besteden aan dienst werden geteld. Dit aantal is geëxtrapoleerd, waarbij is uitgegaan van de eerste vier jaar van de opleiding omdat daarna, zeker in de toekomst, de opleiding kan worden voortgezet in een aandachtsgebied en dus de eindtermen van het Raamplan inmiddels gehaald moeten zijn.

\section{Behaalde eindtermen}

\section{Algemene eisen}

Iedere auteur heeft aan de hand van het Raamplan vastgesteld welke algemene eisen volgens hem of haar tijdens de diensten geleerd kunnen worden. Daarnaast is iedere auteur gevraagd om vast te stellen welke eindtermen alleen tijdens de dienst geleerd kunnen worden. Alle auteurs zijn actief bij onderwijs en opleiding betrokken. Zij hebben een ruime ervaring met de in diensten aangeboden patiëntenpopulatie en met de werkwijze tijdens de diensten. Aan een drietal assistent-geneeskundigen, bekend met de gebruikte terminologie, zijn dezelfde vragen voorgelegd.
Klinische presentaties en ziektebeelden Alle patiënten die zich op de centrale spoedopvang van het Academisch Ziekenhuis Groningen melden met een hulpvraag, worden ingeschreven in het ziekenhuis informatiesysteem. Alle patiënten die buiten kantooruren worden ingeschreven voor de interne geneeskunde worden geregistreerd. Uit dit aanbod selecteerde de voorzitter van het ochtendrapport in samenspraak met de dienstdoende assistent-geneeskundige de voor de opleiding of bedrijfsvoering relevante patiënten voor presentatie. Selectie vond ook plaats om tijd te maken voor gestructureerd onderwijs. ${ }^{10}$ De voorzitter van het ochtendrapport codeerde vervolgens de klinische presentatie én het ziektebeeld van elke patiënt conform het Raamplan. Er was een beperkte groep voorzitters die onderling afspraken maakte over de coderingssystematiek. De onderzoeksperiode besloeg het hele jaar 2001 .

Om de waarde voor de opleiding vast te stellen, zijn een aantal aannames gedaan. Gesteld is dat een assistent-geneeskundige tijdens de opleiding minimaal 2 keer in aanraking moet komen met een bepaalde eindterm om deze op grond van patiëntencontacten te beheersen. De kans dat een assistent-geneeskundige met een bepaalde eindterm in aanraking komt kan worden berekend. Als er van wordt uitgegaan dat de frequentieverdeling volgens een Poissonverdeling verloopt dan zou, bij een bezetting van gemiddeld 18 assistent-geneeskundigen, de incidentie van een klinische presentatie of ziektebeeld 16 per jaar moeten zijn om elke assistentgeneeskundige met $80 \%$ waarschijnlijkheid 2 keer tijdens diensten in de opleidingsperiode van 4 jaar met deze eindterm in aanraking te laten komen: 


$$
\text { N/A }-0,8416 \sqrt{ } \text { N/A }>\text { X }
$$

$\mathrm{N}($ de te berekenen factor $)=$ de incidentie (uitkomst is $64 / 4$ jaar, 16 jaar)

$\mathrm{A}=$ het aantal assistent-geneeskundigen, gesteld op 18

$0,8416=$ de omrekeningsfactor horend bij $80 \%$ waarschijnlijkheid

$\mathrm{N} / \mathrm{A}=\lambda$, de s.d. van een Poissonverdeling

$\mathrm{X}=$ het aantal gevallen per assistent-geneeskundige, gesteld op 2

Omdat de meeste patiënten echter door meerdere assistent-geneeskundigen worden gezien, is de incidentie waarbij aangenomen mag worden dat assistent-geneeskundigen met een bepaalde eindterm 2 keer in aanraking komen tijdens de diensten op 10 per jaar gesteld. Bovendien is er ook een leereffect voor de niet direct betrokken assistent-geneeskundigen, tijdens de bespreking op het ochtendrapport. ${ }^{8}$

\section{Subjectieve waardering}

Drie assistent-geneeskundigen, vergevorderd in de opleiding, werd verzocht om, in het kader van een op organisatorische aspecten gericht onderzoek, in open vragen aan te geven wat voor hen in positieve en negatieve zin de waarde was van het doen van diensten.

\section{Resultaten}

\section{Patiëntenaantallen per tijdseenheid}

Het aantal uren dienst in de eerste vier jaar van de opleiding bedraagt 315 uur per jaar. Het aantal patiënten dat in totaal op de spoedopvang werd ingeschreven in het jaar 2001 bedroeg 27.254. Door de assistent-geneeskundigen van de algemene interne geneeskunde werden tijdens de onderzoeksperiode 3.144 patiënten op de acute opvang gezien, waarvan 1.605 tijdens de diensturen. Van deze 1.605 patiënten werden er 711 opgenomen. Van 1.165 patiënten werden 2.330 eindtermen (klinische presentaties én ziektebeelden) geregistreerd. De overige 440 patiënten werden noch vanwege bedrijfsvoering, noch vanwege opleidingsaspecten geselecteerd voor presentatie op het ochtendrapport. Alle 711 opgenomen patiënten en 454 niet opgenomen patiënten werden gepresenteerd en gecodeerd.

Tijdens de diensten ziet de assistentgeneeskundige van de algemene interne geneeskunde gemiddeld 1 patiënt per 239 minuten. Dit betekent dat elke assistentgeneeskundige 79 patiënten per jaar ziet tijdens de diensten. Tijdens kantooruren wordt door de assistent-geneeskundige 1 nieuwe patiënt per 91 minuten gezien op de afdeling spoedeisende hulp.

\section{Behaalde eindtermen}

\section{Algemene eisen}

In tabel 1 zijn de algemene eisen weergegeven, waarvan de auteurs en de assistent-geneeskundigen van mening zijn dat ze tijdens de diensten worden geleerd. De eindterm die alleen tijdens dienst wordt geleerd staat cursief gedrukt. De algemene eisen worden weergegeven als zij door minstens twee auteurs of assistent-geneeskundigen zijn genoemd. De terminologie is conform het Raamplan. Omdat volledige overeenstemming bestond tussen specialisten en assistent-geneeskundigen zijn deze uitkomsten samengevoegd. ${ }^{7}$

Tabel 1. Algemene eisen tijdens de dienst te leren.

- Specialistische kennis op het gebied van diagnostiek.

- Probleemoplossend vermogen.

- Informatie aan de patiënt en diens omgeving.

- Therapeutisch beleid.

- Farmacotherapie.

- Intoxicaties / verslaving.

- Procedures en vaardigheden.

- Perioperatieve zorg.

- Verslaglegging, verslaggeving. 
In tabel 2 worden alle klinische presentaties en ziektebeelden weergegeven, ook conform het Raamplan, die zich tijdens de dienst in de onderzoeksperiode vaker dan 10 maal hebben voorgedaan. Patiënten die niet geselecteerd werden voor presentatie hadden met name eenvoudige pathologie, zij presenteerden zich bij herhaling met hetzelfde probleem of hun problematiek was recent ook al in een ander verband besproken.

\section{Subjectieve waardering}

In tabel 3 staan de antwoorden weergegeven van de assistent-geneeskundigen op de vragen wat voor hen in positieve of negatieve zin de waarde is van het doen van diensten. De antwoorden komen niet overeen met de terminologie van het Raamplan omdat hier open vragen zijn gesteld.

Tabel 2. Klinische presentaties en ziektebeelden te behalen tijdens diensten.

\section{Acute interne geneeskunde}

- Intoxicaties/overdosis

- Coma diabeticum

- Sikkelcelcrisis

- Pneumonie

- Sepsis (shock)

- Respiratoire insufficiëntie

- Longembolie/veneuze trombose

- Bloedverlies tractus digestivus

- Acute pancreatitis

- Acute buik

- Nierinsufficiëntie

\section{Allergologie en immunologie \\ Ziektebeeld \\ - Geneesmiddelenallergie}

Water- en electrolythuishouding

Klinische presentatie

- Afwijkende hydratietoestand

\section{Endocrinologie/stofwisselingsziekten}

Klinische presentatie

- Hyper-/hypoglycaemie

\section{Ziektebeeld}

- Diabetes mellitus

\section{Hart- en vaatziekten}

Klinische presentaties

- Pijn op de borst

- Dyspnoe

\section{Ziektebeelden}

- Decompensatio cordis

- Diepe veneuze thrombose

\section{Longziekten}

155

11

11

20

10

11

17

54

18

18

11

- Icterus

Icterus

- Buikpijn

- Haematemesis

- Rectaal bloedverlies

- Melaena

- Diarrhee

Ziektebeelden

10 - Diarrhee

- Ulcuslijden

- Gastro-intestinaal bloedverlies

- Inflammatoire darmziekten

23

- Diverticulose/diverticulitis

- Galsteenlijden

- Galgangobstructie

24 - Levercirrhose

- Hepatitis

- Pancreatitis

- Coprostase

17

\section{Nierziekten}

Ziektebeelden

- Acute nierinsufficiëntie

- Chronische nierinsufficiëntie 


\section{Vervolg tabel 2.}

\section{Haematologie}

Klinische presentaties

- Bleekheid, moeheid

- Koorts bij neutropenie

- Veneuze thrombose

Ziektebeelden

- Anaemiën

- Stollingsstoornis

- Thrombopenie

- Acute leukemie

- Maligne lymphomen

\section{Infectieziekten}

Klinische presentaties

- Koorts (febris e.c.i) 52

- Koorts bij neutropenie

- Diarrhee/braken

- Cellulitis

\section{Ziektebeelden}

- Sepsis

- Luchtweginfecties

- Infecties maag- darmkanaal

- Urineweginfecties

- Virale infecties

- Febris e.c.i.

- Huidinfecties
- Koorts bij immunosuppressie

\section{Oncologie}

Klinische presentatie

- Bloeding

\section{Reumatologie}

Klinische presentatie

- Pijnlijk gewricht

\section{Neurologie}

Ziektebeeld

- Toxische encephalopathie

\section{Psychiatrie}

Klinische presentaties

- Alcoholisme 20

- Verwardheid 12

- Suïcidaal gedrag 55

17 Ziektebeelden

11 - Delier 13

Interne geneeskunde van de oudere patiënt

Klinische presentatie

- Valneiging

Ziektebeelden

- Geneesmiddelenintoxicaties 24

Tabel 3. Subjectieve meningen van assistentBespreking geneeskundigen over de waarde van het doen van dienst.

\section{Positief}

- Onderhouden vaardigheden.

- Gevoel van groei.

- Leren snel te handelen.

- Leren omgaan met gespecialiseerde verpleging.

- Leren omgaan met acute ziektebeelden.

\section{Negatief}

- Discontinuïteit in de stages veroorzaakt door diensten.
Evaluatie van leermiddelen zoals klinische stages en cursussen is noodzakelijk, omdat er een toenemende behoefte is om opleidingen efficiënter en effectiever te maken. Vooral bij klinische activiteiten, zoals diensten, met ook een duidelijk element van bedrijfsvoering is goede analyse noodzakelijk. Het tijdsbeslag door diensten is groot. Het totaal aan diensturen in de eerste vier jaar van de opleiding komt ongeveer overeen met twee stages van vier maanden. In Nederland wordt tijd die besteed wordt aan diensten gecompenseerd in vrije tijd. Daardoor komen andere, van- 
uit opleidingsperspectief relatief efficiëntere opleidingsmomenten te vervallen. Een exacte bepaling van de werklast wordt bemoeilijkt door het ontbreken van een goede registratie van het aantal gewerkte uren. Assistent-geneeskundigen worden zodanig ingeroosterd dat aan de Algemene Maatregel van Bestuur wordt voldaan. De op die roostering gebaseerde telling geeft dezelfde uitkomst als een berekening gebaseerd op het totaal aantal diensturen gedeeld door het aantal beschikbare assistent-geneeskundigen. Beide bepalingen komen uit op 315-350 diensturen per jaar per assistent-geneeskundige.

Het Raamplan is niet ontworpen om op deze wijze een analyse te maken. De indeling is gebaseerd op bestaande lijnen in de geneeskunde en is niet patiënt of probleem georiënteerd. Deels worden stages en bestaande aandachtsgebieden gevolgd, deels worden ziektebeelden gegroepeerd, zoals elektrolytstoornissen, en soms worden patiëntenkarakteristieken zoals leeftijd, gebruikt. Daarom komen sommige eindtermen op diverse plaatsen voor. Het ontbreken van exacte omschrijvingen maakt dat indeling soms arbitrair is. Toch kan uit de codering, gebaseerd op het Raamplan, de conclusie worden getrokken dat de pathologie zoals die in diensten aan de orde komt betrekkelijk eenvormig is. De voor de opleiding noodzakelijke variatie is beperkt. ${ }^{11}$ Enkele klinische presentaties en ziektebeelden komen frequent voor, vaker dan voor de opleiding noodzakelijk is. Logischerwijs betreft het vooral eindtermen uit het hoofdstuk 'Acute geneeskunde' van het Raamplan. ${ }^{7}$ Een voorbeeld hiervan is de intoxicatie. Zeldzamere ziektebeelden zijn inderdaad zeldzaam en daarom is de kans dat elke assistent-geneeskundige er tijdens de dienst mee in aanraking komt onvoldoende gegarandeerd. Het doen van diensten is daarmee niet de methode om met zeldzame aandoeningen te leren omgaan. Overigens is voor het leren van de meeste eindtermen niet bekend hoe vaak iemand hiermee in aanraking moet komen om deze eindterm te beheersen. Het aantal van 2 gedurende de 4 jaar van de basisopleiding is daarom een aanname.

Voor de algemene eisen is de efficiëntie voor het bereiken van de eindtermen moeilijker vast te stellen, omdat hierbij subjectieve methoden voor het behalen van eindtermen worden gebruikt. Er bestaat echter een opvallende overeenstemming over het feit dat alleen voor het behalen van de algemene eis 'intoxicatie en verslaving' uit het Raamplan, het doen van dienst de unieke gelegenheid is. ${ }^{7}$ Daarnaast is er een groot aantal andere algemene eisen die ook tijdens het doen van dienst aan de orde kunnen komen. De omstandigheden tijdens de dienst zijn weliswaar iets anders, maar in essentie kunnen deze algemene eisen tijdens vele andere, in de opleidingseisen verplichte, opleidingsmomenten ook worden behaald. Deze analyse laat zien dat voor het behalen van specifieke eindtermen, klinische presentaties en ziektebeelden, het doen van dienst een inefficiënte methode is. Voor het bereiken van de meeste algemene eisen zijn andere leermiddelen c.q. stages ook geschikt en door het grotere patiëntenaanbod waarschijnlijk ook efficiënter. Hiervoor zijn twee belangrijke oorzaken. Het doen van dienst is een paraatheidsfunctie. Dit betekent dat er regelmatig gewacht wordt op dingen die zouden kunnen gebeuren. ${ }^{12}$ Onderzoek in het buitenland laat zien dat maximaal de helft van de tijd in de periode tussen 19.00 uur en 7.00 uur besteed wordt aan patiëntenzorg. ${ }^{13-15} 512$ Administratieve procedures en handelingen bij de patiënt, zoals bloedafname en het inbrengen van een infuus, zijn hierbij gerekend als patiën- 
tenzorg. De tweede oorzaak is de eenvormigheid van de pathologie, waardoor maar een beperkt aantal eindtermen wordt bereikt.

Of het doen van diensten ook effectief is laat zich niet goed beantwoorden. Effectief betekent dat het beoogde effect ook behaald is. Omdat er alleen een globaal toetsings- en beoordelingssysteem is, wordt effectiviteit tijdens de hele opleiding nauwelijks bepaald. Dit zal tijdens de diensten meestal nog minder gebeuren, omdat het grote aantal supervisoren en de versnippering in de tijd toetsing en beoordeling sterk belemmeren.

Assistent-geneeskundigen waarderen het doen van dienst vooral, omdat het hen een gevoel van zelfstandigheid geeft en ze gedurende de opleiding in toenemende mate het gevoel bevestigd zien dat ze wat kunnen. ${ }^{4}$ Dit is waardevol maar kan ook op andere wijze, door het geven van toenemende verantwoordelijkheid tijdens de stages, worden verkregen. Een gemoderniseerde meester-gezel relatie, waarin de aandacht meer gericht is op de actuele opleidingsbehoefte van de assistent-geneeskundige dan op de bedrijfsvoering zou hiervoor een oplossing kunnen zijn. 611

Onderwijskundig zijn er twee kanttekeningen te plaatsen bij het doen van dienst. Ook in de toekomst zal het meester-gezel model een belangrijke rol blijven spelen in de opleiding. ${ }^{11}$ Echter, tijdens diensturen functioneert dit niet optimaal, omdat de achterwacht (de meester) meestal alleen op afroep beschikbaar is. Deze achterwacht heeft bovendien niet altijd grote affiniteit met acute geneeskunde. ${ }^{5}$ Het eerste jaar van de opleiding is vooral bedoeld voor het aanleren van de algemene eisen. ${ }^{9}$ Dit gebeurt het beste in een omgeving waar supervisie onder handbereik is. Bovendien zullen assistent-geneeskundigen in het eerste jaar van de opleiding nog weinig kennis hebben van specifieke eind- termen. Omdat tijdens dienst juist een integratie nodig is van algemene eisen en specifieke eindtermen zal het rendement voor een beginnende assistent-geneeskundige niet optimaal zijn.

Tijdens de diensten worden meestal ook consulten ten behoeve van andere specialismen verricht en wordt zorg gedragen voor opgenomen patiënten met acute problemen. Het potentiële leereffect hiervan is buiten beschouwing gelaten, omdat dit niet wezenlijk anders is dan tijdens de verplichte stages die binnen kantooruren worden gedaan.

Ook in andere landen vindt reductie van excessieve werktijden plaats. Ook daar blijkt dat het doen van diensten, die gecompenseerd worden in vrije tijd, nadelig is voor de opleiding. ${ }^{16}$ Een moratorium op de invoering van compensatie in vrije tijd, zoals door sommigen wordt bepleit, is echter in Nederland alleen al op wettelijke gronden een gepasseerd station.

In de aangepaste opleidingseisen die ter beoordeling aangeboden zijn aan de Medisch Specialisten Registratie Commissie (MSRC) is sprake van de mogelijkheid van een stage acute geneeskunde. Hiermee wordt een oplossing geboden voor een aantal problemen. Als de stage grotendeels tijdens kantooruren wordt gevolgd, is het patiëntenaanbod veel groter en waarschijnlijk ook gevarieerder. Daarmee neemt de efficiëntie toe. Omdat supervisie constanter in kwaliteit en kwantiteit is, is de effectiviteit beter te beoordelen en waarschijnlijk ook hoger. Als deze stage later in de opleiding plaatsvindt, is het rendement voor de assistentgeneeskundige ook groter, omdat dan vooral aandacht kan worden gegeven aan de specifieke eisen en de integratie hiervan met de algemene eisen.

Bij de discussie over de waarde van diensten is het bedrijfsvoeringsaspect tot nu toe buiten beschouwing gebleven. Het 
is een paraatheidsfunctie die niet opgeheven kan worden. Als daarom assistent-geneeskundigen minder in diensten worden ingezet om de efficiëntie en effectiviteit van de opleiding te verbeteren, dan moet de bedrijfsvoering wel verzekerd zijn en blijven.

Concluderend kan worden gesteld dat vanuit het oogpunt van efficiëntie en effectiviteit er betere methoden zijn om de eindtermen uit het Raamplan te behalen dan het doen van diensten. De eindtermen die betrekking hebben op acute geneeskunde zijn effectiever en efficiënter te leren in een stage acute geneeskunde. Dan komen ook onderwijskundige principes beter tot hun recht. Tijdens de opleiding zou er meer aandacht moeten zijn voor de progressie ten aanzien van de algemene eisen van de assistent-geneeskundige om het subjectieve gevoel van voortgang te ondersteunen.

\section{Dankbetuiging}

Dr. W.J. Sluiter gaf waardevol statistisch advies. Dr. G.W. van Imhoff, prof. dr. P.E. de Jong, dr. J.C. ter Maaten, prof. dr. J.G.R. de Monchy en dr. J.E. Tulleken hebben als voorzitter van het ochtendrapport belangrijk bijgedragen aan de dataverzameling. Dr. S. Hovenga en mw. dr. A.K.L. Oei-Reyners hebben als lid van de projektgroep Revisie Opleiding Interne Geneeskunde een belangrijke bijdrage geleverd aan de discussie en de dataverzameling.

\section{Literatuur}

1. Wood VC, Markert RJ, McGlynn TJ. Internal medicine residents' perceptions of the balance between service and education in their night-call activities. Acad Med 1993;68:640-2.

2. Wallace EZ. Service vs education in internal medicine residency. Need for a resolution. Arch Intern Med 1988;148:1296.

3. Dresselhaus TR, Luck J, Wright BC, Spragg RG, Lee ML, Bozzette SA. Analyzing the time and value of housestaff inpatient work. J Gen Intern Med 1998;13:534-40.
4. McKee M, Black N. Does the current use of junior doctors in the United Kingdom affect the quality of medical care? Soc Sci Med 1992;34:549-58.

5. Nerenz D, Rosman H, Newcomb C, Bolton MB, Heudebert G, Simmer T, Goldstein S. The on-call experience of interns in internal medicine. Medical Education Task Force of Henry Ford Hospital. Arch Intern Med 1990;150:2294-7.

6. Meyboom-de Jong B, Schmit Jongbloed LJ, Willemsen MC. De arts van straks. Utrecht: KNMG/VSNU/VAZ/NVZ/LCVV; oktober 2002.

7. Raamplan Interne Geneeskunde 2002. Alphen aan de Rijn: Van Zuiden; 2002.

8. Kruijf EJFM de, Meijer PHEM de, Meinders AE. De rol van het ochtendrapport in de opleiding tot internist. Ned Tijdschr Geneeskd 2000;144:1284-7.

9. Opleidingseisen voor het specialisme Inwendige Geneeskunde. In: Jaarboek NIV 2002. Alphen a/d Rijn: Nederlandse Internisten Vereniging; 2002. p. 55-122.

10. Gans ROB, Sleijfer DTh, Werf TS van der, Zijlstra JG. De rol van het ochtendrapport in de opleiding tot internist. Ned Tijdschr Geneeskd 2000;144: 1753-4.

11. Holdrinet RSG, Bulte JA, Bolhuis S. Opleiden van de specialist van straks. Medisch Contact 2002; 57:1688-93.

12. Chalasani K, Nettleman MD, Moore SS, MacArthur S, Fairbanks RJ, Goyal M. Faculty misperceptions about how residents spend their call nights. JAMA 2001;286:1024.

13. Moore SS, Nettleman MD, Beyer S, Chalasani K, Fairbanks RJ, Goyal M, Carter M. How residents spend their nights on call. Acad Med 2000;75: 1021-4.

14. Lurie N, Rank B, Parenti C, Woolley T, Snoke W. How do house officers spend their nights? A time study of internal medicine house staff on call. N Engl J Med 1989;320:1673-7.

15. McKee M, Black N. Junior doctors' work at night: what is done and how much is appropriate? J Public Health Med 1993;15:16-24.

16. Kapur N, House A. Working patterns and the quality of training of medical house officers: evaluating the effect of the 'new deal'. Med Educ 1998;32:432-8.

De auteurs:

Dr. J.G. Zijlstra is internist-intensivist en plaatsvervangend opleider interne geneeskunde.

Drs. M. Stegeman is psycholoog.

Prof. dr. D.Th Sleijfer is internist-oncoloog en hoogleraar klinisch onderwijs.

Dr. T.S. van der Werf is longarts-intensivist.

Prof. dr. R.O.B. Gans is internist, hoogleraar interne geneeskunde en opleider interne geneeskunde.

Allen zijn werkzaam in het Academisch Ziekenhuis Groningen. 
Correspondentieadres:

Dr. J.G. Zijlstra, Interne Kliniek, Academisch Ziekenhuis Groningen, Postbus 30.001, 9700 RB Groningen, j.g.zijlstra@int.azg.nl.

\section{Summary}

Introduction: The training in internal medicine is in a phase of renewal in which efficiency and efficacy are greatly emphasized. It is therefore important to evaluate the contribution of all parts of the training and the time involved. In this paper we describe the contribution of on-call activities to the training in internal medicine. Method: The pathology presented during on-call hours is categorised using the description of competencies for internists. The total workload of on-call activities is measured.

Results: The pathology seen outside office hours appears to be rather uniform. The hours spent performing on-call activities during the whole training period equals about eight months of office hour activities.

Discussion: On-call activities are therefore not an efficient part of the training in internal medicine. Efficacy is not measured during the training, but in view of the fragmentary supervision outside office hours, it is probably not optimal. The competencies that are learned during on-call periods may be learned in a much more efficient way during an acute care rotation. (Zijlstra JG, Stegeman M. Sleijfer DTh, Werf TS van der, Gans $R O B$. What is the contribution of on-call activities to the training in internal medicine? Dutch Journal of Medical Education 2003;22(6): 258-267.) 